\title{
Increased obstetric activity: a new meaning to "induced labour"?
}

\author{
SIGNILD VALLGÅRDA \\ From the Institute of Social Medicine, University of Copenhagen, Denmark.
}

ABSTRACT This study examines the possible reasons for increased obstetric activity in Denmark over the past 25 years. Since 1960 there has been a substantial increase in the average number of hospital admissions (from 10 to 32 per 100 deliveries), in deliveries diagnosed as complicated (from 15 to $49 \%$ ), and above all in major interventions at delivery (from 4 to $22 \%$ ). In spite of this increase in activity there is no evidence that the postwar trend of decreasing perinatal mortality has been further improved during the period of study. It seems possible that the rising level of activity is the result of increasing availability of new technology, decreasing numbers of deliveries and unchanged obstetric staffing levels, with an increased tendency to diagnose and intervene in "at risk" pregnancies. There is a need to determine how the current level of obstetric activity has arisen. Since there is evidence for an increased expectation of intervention by pregnant women, the theory of supplier induced demand may be among the leading contenders to be tested.

During the last 25 years there has been a remarkable rise in Denmark in the number of hospital admissions during pregnancy, in the proportion of deliveries diagnosed as complicated and in the frequency of intervention in these deliveries. In this paper some of the reasons for this development are discussed. It is argued that it is very difficult to determine what factors influence the quality of birth. It is not suggested that the increase in obstetric intervention is useless. Rather the question is posed: where is the evidence to determine whether or not the results justify the efforts, and consequently the costs?

These developments have parallels in other countries. $^{1-4}$ Consequently this paper draws on discussion internationally about the usefulness of this substantial obstetric activity, and about the problems in determining it. ${ }^{5-12}$

\section{Methods}

To examine these issues, statistics on hospital activities, birth statistics and some demographic data are used.

Regarding the activity data, trends over time in admissions, diagnoses and interventions have been examined and related to the changes in the total number of births, including stillbirths. Admissions during pregnancy were also related to the total number of births, even although some of these pregnancies ended as miscarriages. Since not all miscarriages are registered, the total number of pregnancies could not be established. Admissions in connection with miscarriage were not included. They are registered under a separate heading. Furthermore, the falling perinatal mortality rate, ie, for children who are stillborn or who die during the first week of life, has been investigated.

\section{Results}

During the last 25 years there has been an increase in the number of admissions during pregnancy. As a proportion of the number of births, the rate of admission for complications during pregnancy has increased from $0 \cdot 10$ in 1960 to 0.20 in 1970 and 0.32 in 1985 , ie, it has more than trebled (see table 1). (It should be noted that this does not mean that one in three pregnant women is now admitted to hospital. One woman may have several admissions during the same pregnancy, and during pregnancies resulting in abortion there may have been previous admissions).

An increasing percentage of all hospital deliveries are diagnosed as complicated (see table 2 ), even

Table 1 Hospital admissions during pregnancy. Source: Medical and hospital statistics, National Board of Health.

\begin{tabular}{ll}
\hline Year & $\begin{array}{l}\text { Admissions during } \\
\text { Pregnancy (per birth) }\end{array}$ \\
\hline 1960 & $7574(0 \cdot 10)$ \\
1965 & $11771(0 \cdot 14)$ \\
1970 & $15602(0 \cdot 22)$ \\
1975 & $13338(0 \cdot 18)$ \\
1980 & $15284(0 \cdot 27)$ \\
1985 & $17441(0 \cdot 32)$ \\
\hline
\end{tabular}


Table 2 Deliveries diagnosed as complicated and number of hospital deliveries and deliveries in obstetric wards. Source: Medical Statistics and Medical Birth Register, National Board of Health.

\begin{tabular}{|c|c|c|c|c|}
\hline \multirow[b]{2}{*}{ Year } & \multirow{2}{*}{$\begin{array}{l}\text { Number of complicated } \\
\text { hospital deliveries } \\
\text { (percentage of } \\
\text { births) }\end{array}$} & \multicolumn{3}{|c|}{ Hospital deliveries } \\
\hline & & $\begin{array}{l}\text { Total } \\
\text { No }\end{array}$ & $\begin{array}{l}\text { Percent of } \\
\text { total } \\
\text { deliveries }\end{array}$ & $\begin{array}{l}\text { Obstetric ward } \\
\text { deliveries as } \\
\text { percent of total }\end{array}$ \\
\hline 1960 & $11661(15)$ & 28148 & 37 & - \\
\hline 1965 & $17383(20)$ & 42898 & 50 & - \\
\hline 1970 & $21313(30)$ & 50269 & 71 & 45 \\
\hline 1975 & $24919(34)$ & 61260 & 85 & 57 \\
\hline 1980 & $24129(42)$ & 55001 & 96 & 73 \\
\hline 1985 & $26467(49)$ & 53431 & 99 & 78 \\
\hline
\end{tabular}

though today almost all women give birth in hospital $(99 \%)$, compared to $41 \%$ in 1960 . In 1960 it was primarily women in so called risk groups who were admitted to hospital for delivery. Consequently a higher percentage of complicated hospital deliveries at that time would be expected. But this is not the case. In $196041 \%$ of hospital deliveries were considered to be complicated while in 1985 the figure was $49 \%$. Comparing the number of complicated hospital deliveries with the total number of deliveries, there is an increase from $15 \%$ in 1960 to $48 \%$ in 1985 . Of course there were complicated deliveries outside hospital before, but that, by itself, cannot explain much of the increase. The number of hospital deliveries diagnosed as complicated is probably even higher, as not all deliveries are included in the statistics. Some of them are hidden under other main diagnoses, eg, complications during pregnancy. In recent years $12 \%$ have been concealed in this way.

This change might suggest that the classification of diagnoses has changed. However, at least formally, it has remained the same throughout the whole period. ${ }^{13}$

There is likely to be some connection between diagnosis and intervention. The more women diagnosed as having complicated deliveries, the more interventions will be performed. Or it may be that more interventions lead to more diagnoses of complicated deliveries. In any case, there has been an increase in the number of interventions (see table 3). The rate of caesarean sections rose from $2.0 \%$ in 1960 to $13.0 \%$ in 1985 , and the rate of vacuum extraction and of forceps deliveries from $1.9 \%$ to $9.0 \%$. These increases were most pronounced in the seventies. In $198480 \%$ of all children were delivered through one or more interventions, including minor procedures such as episiotomies.

How can it be that the admission rate during pregnancies has trebled, that the number of deliveries diagnosed as complicated has probably trebled and the number of deliveries conducted by caesarean section, vacuum extraction and forceps have increased more than fivefold in 25 years? Two reasons come immediately to mind:

(1) Women are becoming less capable of giving birth, due to deteriorated health status, or for other reasons.

(2) Better health and survival have been observed as a result of the activity.

These are now examined. Because of limitations in the availability of relevant statistics, only a limited number of factors can be included.

Table 3 Number of caesarean sections, etc, and (percentage of total number of deliveries). Source: Medical Statistics and Medical Birth Register, National Board of Health.

\begin{tabular}{lll}
\hline Year & Caesarean sections & $\begin{array}{l}\text { Vacuum extractions and } \\
\text { forceps deliveries }\end{array}$ \\
\hline 1960 & $1533(2 \cdot 0)$ & $1219(1 \cdot 9)$ \\
1964 & $1998(2 \cdot 4)$ & $1098(1 \cdot 3)$ \\
1970 & $2907(4 \cdot 0)$ & $2500(4 \cdot 0)$ \\
1974 & $4332(6.0)$ & $4245(6.0)$ \\
1979 & $6146(10.0)$ & $5533(9 \cdot 0)$ \\
1985 & $6673(13 \cdot 0)$ & $4884(9 \cdot 0)$ \\
\hline
\end{tabular}

There is no immediately relevant information on the general health status of Danish women in the childbearing ages to show whether it has improved or not. The average length of life has been rising continually among women.

Since there are so few measures of women's health status, factors known to have an influence on health have been examined, for example housing conditions. Dwellings are less crowded. In 1935 there was an average of 3.3 persons per habitation with three rooms, in 1960 3.0 , and in 19812.0 . The number of dwellings with both bath and central heating was about $22 \%$ in 1935 , $45 \%$ in 1960 and $83.3 \%$ in 1981 . These factors should have had a positive influence on health status.

From 1973 the law on free abortion up to the 12th week would have been expected to have the effect that fewer women in poor social conditions would have given birth and fewer unwanted children born. This would have had a positive influence on the circumstances surrounding the delivery.

The greater participation of women, particularly married women, in the labour force may have had the opposite effect. Work and the work environment may have had adverse effects on the health status of women.

Two factors which might have influenced the pregnancy and birth can be investigated through existing statistics, the age of the mother and parity. More of the women giving birth were aged 20-29 years in 1985 than in 1960, but fewer than at the peak in the seventies (table 4). The numbers of primiparous women have risen, together with the rate of primiparity in women over 30 years of age. At the same time the number of women with high parity, four or more deliveries, has declined. 
Table 4 Parity and age of the women giving births as a percentage of all women giving birth. Source: Statistical Yearbook, Population Movements, and Medical Birth Register.

\begin{tabular}{lcccl}
\hline & Primipara & $\begin{array}{l}\text { Primipara } \\
>30 \text { years }\end{array}$ & $\begin{array}{l}\text { Para 4 } \\
\text { or more }\end{array}$ & $\begin{array}{l}\text { Aged 20-29 } \\
\text { years at } \\
\text { delivery }\end{array}$ \\
\hline 1960 & - & - & - & 62.5 \\
1965 & 36.5 & 2.0 & 15.6 & 65.8 \\
1970 & 36.9 & 1.9 & 11.9 & 71.6 \\
1975 & 44.6 & 3.1 & 5.5 & 73.0 \\
1980 & 44.7 & 4.2 & 4.4 & 69.7 \\
1985 & 46.7 & 6.3 & 4.1 & 67.2 \\
\hline
\end{tabular}

There is no immediate reason to believe that the general health status of the wumen has deteriorated, rather the contrary. Concerning the age and parity of the mothers the evidence is not clear cut. But the overall tendency would point to an improvement. It is unlikely that it was because of deteriorated health that treatment activity has increased.

The other possible explanation mentioned above was that there had been a decline in morbidity and mortality due to the rise in the treatment activity. Maternal mortality has been too low during this period to show any significant changes. No information appears to be available on maternal morbidity. However since the fifties a reduction in perinatal mortality and morbidity has been the main focus of obstetric activity. As some Danish obstetricians have expressed it:

"The main focus of obstetrics has changed over time. Not more than a generation ago it was the reduction of maternal mortality which was in focus. After that the perinatal mortality was the main problem. This is slowly changing into a period where the most important issue is to have as few children as possible with multifactoral causes of morbidity in pregnancy."14

"Perinatal mortality is a measure of the standard of the obstetric service in an area."15

On the morbidity of children there is some information, albeit limited. There has been a fall in the frequency of cerebral palsy from 2.6 per thousand in the fifties, when it was first registered, to 1.7 per thousand in the mid seventies. Since then there has been a small rise to $2 \cdot 0$ per $1000 .{ }^{16}{ }^{17}$ However it is not possible to tell from the available literature what share of handicaps at birth is due to events during delivery and how much to circumstances before that. In the article cited ${ }^{17}$ the fall is explained by improved obstetric and neonatal care, while the more recent rise is explained by the rising number of very small children surviving.
The proportion of multi handicapped children, with both mental and physical handicaps, has been rising in the period from 1970 to 1985 in the county of Copenhagen. ${ }^{18}$

The incidence of children with Down's syndrome has been rising from 1980 to 1985 in Denmark in spite of abortions made after amniocentesis. (Older women now give birth to a smaller proportion of the Down's syndrome children than before. ${ }^{19}$ )

From the few studies made it seems that the health of children has been deteriorating since the beginning of the seventies. Not least the rising incidence of Down's syndrome indicates a deterioration outside the domain of obstetric care. At the same time it might be argued that the development in children's health status might have been worse without these interventions.

The most universal and clear cut measure available on the quality of birth is the perinatal mortality rate. This has been falling during the period investigated but no more so than during the previous decades (see figure). From the 1920s to the beginning of the 1940s there was a small rise in perinatal mortality ino Denmark. During the war it started falling. The reasons are unknown. It has continued to fall since् then at various rates in different periods. In the last $\$$ years the fall has been small. Reducing it furtheg 3 becomes increasingly more difficult.

Figure Perinatal mortality rate in Denmark 1921-1986

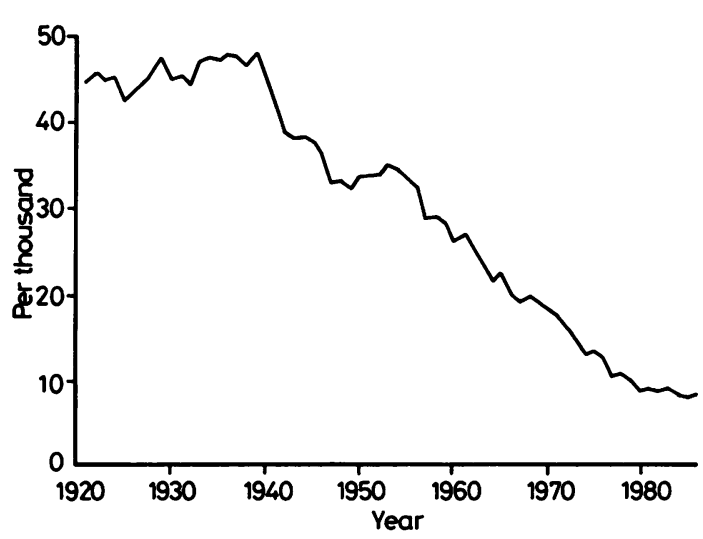

Infant and Perinatal Mortality in Denmark. Vital and Health Statistics National Center for Health Statistics, Series 3 Number 9 Washington 1967, Medical Statistics and Medical Birth Register. National Board of Health.

The factor that has the biggest single influence on perinatal mortality is the number of preterm and/or low birthweight children. Until the beginning of the seventies prematurity was measured by birth weight 
Table 5 Percentage of births weighing less than $2500 \mathrm{~g}$. Source: Medical Statistics and Medical Birth Register, National Board of Health.

\begin{tabular}{ll}
\hline 1960 & $6 \cdot 2$ \\
1965 & $6 \cdot 2$ \\
1970 & $6 \cdot 0$ \\
1974 & 6.8 \\
1981 & 5.8 \\
1985 & 5.9 \\
\hline
\end{tabular}

between 1000 and $2500 \mathrm{~g}$. The percentage of underweight children has generally been falling since the mid seventies (see table 5). The number of preterm births has been registered since 1972, from which time it has been falling. It is generally accepted that the numbers of "premature" births are influenced by social conditions, housing, diet, etc. Consequently, maternity care can only have contributed to a part of the reduction in the number of premature births. ${ }^{20}$ Thus at least some of the fall in mortality can be explained by fewer preterm and/or low birthweight births.

Obstetric activity might have influenced the perinatal mortality rate but other factors might have as well, for example the age and parity of the mothers. A Swedish study ${ }^{21}$ found that about one tenth of the fall in the perinatal mortality rate could be explained by the lower parity and age of the mother. Because the decrease in parity has been somewhat greater in Denmark it might explain more of the decline. There have been fewer "premature" births in recent years. As shown, there has been a fall in the perinatal mortality rate since the beginning of the 1940s, long before obstetric activity rose. Further, there is no immediate correlation between the very substantial rise in obstetric activity since the mid seventies and the fall in the perinatal mortality rate.

\section{Discussion}

Since there is no clear evidence that the substantial rise in obstetric activity is justified by deteriorating health or increased effectiveness, what other explanations can there be for the rise?

Probably the most important is that doctors and others believe there is an effect, even though it is not documented. In discussing the effect of an activity it is often possible to confuse the declared objectives with the result. Even though it is the declared objective of the obstetrician to reduce perinatal mortality, any reduction is not necessarily a result of their efforts, or of their efforts alone.

The numbers of deliveries have fallen from 76000 in 1960 to 540001985 . Thus the work load has diminished. The share of hospital deliveries has risen, as has the share of deliveries in obstetric departments (table 2). It has been shown that the rate of interventions is higher in obstetric departments. ${ }^{22}$ The number of consultants in obstetrics and gynaecology has quadrupled, while the overall number of consultants has trebled. (Obstetrics and gynaecology cannot be separated in the statistics.) A French study has indicated that women looked after by specialists have more admissions during pregnancy than those looked after by general practitioners. ${ }^{23}$ The number of beds rose until 1980, but since then it has been falling, as has the number of admissions and deliveries. However the number of consultants has not fallen, while technological and laboratory equipment for diagnosis, supervision and treatment has grown substantially. New technology, eg, electronic fetal monitoring, leads to more interventions. ${ }^{24} 25$ More resources, specialists and equipment, and fewer deliveries probably lead to a higher degree of intervention in each pregnancy and delivery.

There is a general tendency to focus more on risk. This is illustrated by the sharp increase in the number of deliveries diagnosed as complicated. In Denmark in 1962 two out of every three women giving birth where expected to be "normal", compared with only one in three in $1970 .^{26} 27$ Specialists have taken over more antenatal care and attend birth more frequently, and they are more inclined to indentify women as being at risk than are midwives. ${ }^{28}$ As Huberts et al ${ }^{23}$ state: "By training, specialists have an approach to pregnancy focused on risks". Of course more knowledge may lead to changed attitudes and more potential risks become known through time. But that does not necessarily lead to more activity, provided doctors are able to judge the risks in each individual delivery.

Women demand more intervention, partly because of expectations fostered by the doctors and partly because they give birth to fewer children. They expect to have a healthy child and believe that the doctors can secure that.

These factors give an explanation for some of the increase in obstetric activity. However they do not appear to represent a sufficient justification for the rise. Economists ${ }^{29} 30$ talk about concept of "supplier induced demand" which might be a fruitful basis on which to build an understanding of the rise in obstetrical interventions. Two great changes have taken place on the supply side: there are more doctors; and they have more equipment and more beds for pregnant women and women giving birth, relatively at least, considering the falling birth rate. Further the doctors have changed their criteria on indications for treatment and intervention, related to more and more stringent categorisation of health problems and definitions of "normal" and "at risk". These changes may have influenced the expectations of the women. Suppliers of obstetric care may have used their position to influence the demand for their 
own efforts and skills in intervention - $a$ form of what might to termed "induced labour". Against the background of fewer births and improved health status of women and the lack of good evidence to justify the steep increase in obstetric intervention, the more plausible - even if not proven - explanation for the phenomenon of rising obstetric activity in Denmark would seem to be "obstetrician induced labour".

Several people have given useful comments. I will particularly thank Gavin Mooney for inspiring and constructive criticism.

Correspondence to: Signild Vallgårda, cand.mag., Research Fellow, Institute of Social Medicine, University of Copenhagen, Blegdamsvej 3, 2200 Copenhagen N, Denmark.

\section{References}

${ }^{1}$ Placek PJ, Taffel S, Moien M. Cesarean section delivery rates: United States, 1981. Am J Public Health 1983; 73: 861-2.

2 Perinatal omsorg $i$ Norden (Perinatal care in the Nordic countries). Copenhagen: Munksgaard, 1985.

${ }^{3}$ Placek PJ, Taffel SM. Cesarean rates increases in 1985. Am J Public Health 1987; 77: 241-2.

${ }^{4}$ Notzon FC, Placek PJ, Taffel S. Comparison of national cesarean-section rates. $N$ Engl J Med 1987; 316: 386-89.

${ }^{5}$ Chalmers I, Oakley A, Macfarlane A. Perinatal health services: an immodest proposal. Br Med J 1980; iii: 842-5.

6 Treffers PE, Laan R. Regional perinatal mortality and regional hospitalization at delivery in the Netherlands. $\mathrm{Br}$ J Obstet Gynaecol 1986; 93: 690-3.

${ }^{7}$ Campell R, Macfarlane A. Place of delivery: a review. Br J Obstet Gynaecol 1986; 83: 675-83.

8 Perinatal care: Organisation and outcome (editorial). Lancet 1986; i: 777-8.

${ }^{9}$ Socialstyrelsen (National Board of Health and Social Welfare). Vården före, efter och under förlossningen. Stockholm, 1986 (With an extensive review of the literature).

${ }^{10}$ Bakketeig L, Hoffman HJ, Sternthal PM. Obstetric service and perinatal mortality in Norway. Acta Obstet Gynaecol Scand (suppl) 1978; 77: 3-19.

11 Grandjean $H$. Determinant of caesarean section. In: Kaminsky M, Brénart G, Buekens P et al eds. Perinatal delivery systems. Oxford: Oxford University Press, 1986; 114-28.

12 Thiery M, Derom R. Review of evaluation studies on caesarean section, Part I; Trends in caesarean section and perinatal mortality. In: Kaminsky M, Bréart G, Buekens P, et al, eds. Perinatal delivery systems. Oxford: Oxford University Press, 1986: 93-113.

${ }^{13}$ World Health Organisation. Manual of the international statistical classification of diseases, injuries and causes of death, 7th revision 1955 and 8th revision 1965. Geneva: WHO.

${ }^{14}$ Kærn T. Visitation af fødepatienter. Ugeskr Lager 1965; 127: 1637-41.

${ }^{15}$ Falck-Larsen J. Obstetrik og gynækologi. Yngre Lager 1967; 13: 140-2.

16 Glenting P. Cerebral parese i østdanmark 1965-1974, 1-5. Ugeskr Lager 1982; 144: 119-24, 2805-11; and 1983; 145: 526-34, 1407-13, 1568-72.

${ }^{17}$ Glenting P. Cerebral parese. In: Born med medfodte handicap. Copenhagen: Egmontfonden, 1986: 116-21.

${ }^{18}$ Hørlyk H, Schultz M, Multihandicappede børn: Stigende hyppighed i Københavnsområdet. Ugeskr Lager 1987; 149: $2165-70$.

${ }^{19}$ Nielsen K, Pilgaard B, Mikkelsen M. Prevalensen og overlevelsen af nyfødte med Downs syndrom i Danmark 1980-85 (Prevalence and survival of newborns with Down's syndrome in Denmark 1980-85). Ugeskr Lager 1987; 149: 2170-3.

${ }^{20}$ Ashford JR, Read KLQ, Riley VC. An analysis of variations in perinatal mortality amongst local authorities in England and Wales. Int J Epidemiol 1973: 2: 31-46.

${ }^{21}$ Meirik O, Smedby B, Ericson A. Impact of changing age and parity distributions of mothers on perinatal mortality $\frac{}{\Phi}+\infty$ in Sweden 1953-1975. Int J Epidemiol 1979; 8: 361-4.

${ }^{22}$ Scherjon S. A comparison between the organisation of $\overrightarrow{\mathscr{D}}$ obstetrics in Denmark and the Netherlands. Br J Obstet Gynaecol 1986; 93: 684-9.

${ }^{23}$ Hubert B, Blondel B, Kaminski M. Contribution of specialists to antenatal care in France: impact on level of care during pregnancy and delivery $J$. Epidemiol Community Health 1987; 41: 321-8.

24 Greenland S, Olsen J, Rachvotin P, Pedersen GT. Effects of electronic fetal monitoring rates of early neonatal death, Apgar score and ceasarean section. Acta Obstet Gynaecol Scand 1985; 64: 75-80.

${ }^{25}$ Leveno KJ. A prospective comparison of selective and universal electronic fetal monitoring in 34,995 pregnancies. $N$ Engl J Med 1986; 315: 615-7.

${ }^{26}$ Kærn T, Ingerslev M. Fødselshjaelpens hovedproblemer. Bibliotek for lager 1962; 154: 25-35.

${ }^{27}$ Ingerslev M. Klinikfødsler i fremtidens sygehusvæsen. Ugeskr Lager 1970; 132: 2453-6.

${ }^{28}$ Vallgårda S. Registrenes pålidelighed. Ugeskr Lager 1987; 149: 754-5.

${ }^{29}$ McGuire A, Henderson J, Mooney G. The economics of health care. London: 1988.

${ }^{30}$ Parkin DW, Yule BF. Economic interpretations of supplier induced demand. Health Economic Research Unit, Discussion paper, University of Aberdeen, Aberdeen, 1984. 